\title{
A Study on Effect of Anaemia on Leucocyte and Platelet Counts in Anaemic and Non Anaemic Young Females at RIMS, Raichur
}

\author{
Authors \\ Dr Ayesha Anjum ${ }^{1}$, Dr Vijay Krishna $K^{2}$, Dr Shivanand K.G ${ }^{3}$ \\ ${ }^{1}$ Postgraduate, Department of Physiology, Raichur Institute of Medical Sciences, Raichur \\ ${ }^{2}$ Head of Department, Department of Physiology, Raichur Institute of Medical Sciences, Raichur \\ ${ }^{3}$ Associate Professor, Department of Physiology, Raichur Institute of Medical Sciences, Raichur \\ Corresponding Author \\ Dr Ayesha Anjum
}

Postgraduate, Department of Physiology, Raichur Institute of Medical Sciences, Raichur Email-anjumayesha40@gmail.com

\begin{abstract}
Background: Nutritional Anaemia is most common nutritional disorder worldwide, and iron deficiency is documented to be the cause in most of the cases. In developing countries, like India, adolescent population is highly vulnerable to suffer iron deficient state. This is mostly due to deficiency of iron, folic acid, zinc and copper etc. It is known that deficiency of these elements affects development and functions of blood cells like impairment of immunity, hampering bactericidal actions of polymorphs; macrophages etc. It is evident from many studies that, anaemia induced hypoxia and ischemia alters leucocytes counts, on other hand, with respect to platelet, thrombocytosis or thrombocytopenia can occur. Thus the aim of this study is to evaluate how anaemic status affects leucocytes and platelet counts in anaemic young females, so that early intervention can avoid further complications.

Materials and methods: The study was done at Raichur Institute of Medical Sciences.20 healthy young females of age group 18-23 years, with haemoglobin level $>12 \mathrm{gm} \%$ were taken as control group. Another set of females of age group 18-23 years, with haemoglobin level less than 6gm\% since two months were taken as study group. Leucocyte and platelet count was done using automated cell counter. Unpaired t test was applied for statistical analysis. $p$ value less than 0.05 was considered significant.

Result: $\mathrm{Hb}$ concentration in anaemic females was $5.52 \pm 1.72 \mathrm{gm} \%$ as compared to $13.62 \pm 1.10$ in control subjects, which was highly significant ( $p<0.01$ ).TLC was high in study group, but no statistical significance $(p>0.05)$.On DLC there was significant rise in neutrophil and basophil counts. Platelet count was significantly low in anaemic subjects $(p<0.05)$. Lymphocyte count was not much altered in anaemic groups.

Conclusion: uses an increase in neutrophil count, but does not significantly increase the total leucocyte count thus, increasing, N/L ratio. It causes a significant decrease in platelet counts. Thus rendering anaemic individuals at risk of ischemic diseases.
\end{abstract}

Keywords: anaemia, leucocyte count, platelet count, haemoglobin. 


\section{Introduction}

Anaemia is decrease in number of red blood cells or haemoglobin in circulation. If there are no enough red blood cells, tissues do not get enough oxygen. In developing countries like India, nutritional anaemia, still haunts and continues to be most common nutritional deficiency. It is well known that, adolscents and women in reproductive age group are most vulnerable to suffer iron deficient status. It is during adolescence, that major part of adult weight and height is achieved. This growth spurt imposes an increased demand of all nutrients, making nutrition of utmost importance for growth and development at this critical age. ${ }^{2}$

A number of factors like, poor dietary intake, low socio-economic status, menstrual blood loss are implicated for the cause of iron deficiency in young females. ${ }^{3}$ Iron is an essential micronutrient, having a direct role in development of lymphoid tissue. Deficiency of iron affects formation and also development of blood cells. Deficiency of iron is found to have a number of adverse effects. Iron deficiency, along with other micronutrient (zinc, selenium, copper) deficiency is documented to hamper bactericidal activity of leucocytes. ${ }^{(4)}$

As the red blood cell counts are low in anaemia, oxygen carrying capacity of blood is also low, thus inducing hypoxia. This hypoxia induced by anaemia increases morbidity and mortality. Variation in WBC counts are implicated as risk factors for majority of vascular diseases ${ }^{(5)}$.With respect to platelets, thrombocytosis or thrombocytopenia can occur in anaemia. Thus present study was done to know how anaemic status affects leucocyte count and platelet counts.

\section{Materials and methods}

The present study was done at Raichur Institute of Medical Sciences.20 females, of age group 1823years, with $\mathrm{Hb}>12 \mathrm{gm} \%$ studying in first phase MBBS, were invited to participate in the study as control group.
Study group includes females of age group 1823years with $\mathrm{Hb}<6 \mathrm{gm} \%$ taken from RIMS Hospital.

After explaining the procedure to them, informed consent was taken. History and clinical examination was done to include or exclude subjects, for the study.

Haemoglobin estimation, total leucocytes count, differential count and platelet count was done using electronic cell counter/L ratio was estimated.

\section{Statistical methods}

Descriptive statistics such as Mean, Standard deviation was used to represent data. All data was expressed as mean \pm standard deviation.Analysis was done by SPSS. p- value less than 0.05 was considered significant.

\section{Results}

On statistical analysis of this study, it was found that, the mean age group was 18 \pm 2.25 . Haemoglobin levels in anaemic females; as compared to control group was $5.82 \pm 1.72$ and $13.62 \pm 1.10$ respectively. This decreased $\mathrm{Hb}$ level in anaemic group as compared to control, which was statistically highly significant. Total leucocyte count was high in anaemic groups, but it was not statistically significant. On analysis of differential leucocytes counts, there was a highly significant rise in neutrophils $(\mathrm{p}<0.01)$, highly significant decrease in monocytes and eosinophil counts $(\mathrm{p}<0.01)$ counts in anaemia. Platelet count was significantly decreased in anaemic subjects/L ratio was significantly higher in anaemic groups $(\mathrm{p}<0.01)$ 
Table 1: Comparision of basic parameters in anaemia and control.

\begin{tabular}{|l|l|l|l|}
\hline Parameters & Anaemia & Control & Significance \\
\hline Age(yrs) & $21.3 \pm 4.2$ & $22.6 \pm 3.8$ & Not significant \\
\hline $\mathrm{Hb}(\mathrm{gm} \%)$ & $5.82 \pm 1.72$ & $13.62 \pm 1.10$ & Highly significant \\
\hline TLC $(\mathrm{cu}$ mm of blood) & $7630 \pm 3304$ & $6878 \pm 1772$ & Not significant \\
\hline $\begin{array}{l}\text { Platelet count( lakhs/cu } \\
\text { mm of blood })\end{array}$ & $1.57 \pm 0.6$ & $3.27 \pm 1.46$ & Significance \\
\hline
\end{tabular}

Table 2: Comparision of differential leucocyte count $\%$ of anaemia and control.

\begin{tabular}{|l|l|l|l|}
\hline Parameters & Anaemia & Control & Significance \\
\hline Neutrophils & $68.79 \pm 92$ & $56.78 \pm 5.54$ & Significant \\
\hline Lymhocytes & $33.61 \pm 11.25$ & $31.15 \pm 3.78$ & Not significant \\
\hline Eosinophils & $2.62 \pm 1.0$ & $5.32 \pm 3.05$ & Highly significant \\
\hline Basophils & $3.0 \pm 1.0$ & $1.8 \pm 0.8$ & Highly significant \\
\hline Monocytes & $2.54 \pm 1.78$ & $7.16 \pm 3.33$ & Highly significant \\
\hline N/L ratio & $1.94 \pm 0.07$ & $1.73 \pm 0.03$ & Highly significant \\
\hline
\end{tabular}

Data presented in mean standard deviation value $<0.05$ not significant value $<0.001$

\section{Discussion}

Nutritional anaemia prevails to be most common cause of preventable nutritional deficiencies in developing countries. it affects the physical, mental, quality of life. It is well known that, children and women in reproductive age group are the most vulnerable to suffer from this iron deficient state It during this age, that more than half of adult parameters are achieved. The role of iron for the growth, and maturation of blood cells is well documented in experimental and also clinical studies. Deficiency of iron adversely affects formation of blood cells. It is documented to cause a reduction in bactericidal activity of macrophages, neutrophils and also monocytes. ${ }^{(6)}$

This study was done on a small sample of subjects, to study effect of anaemia on leucocyte and platelet counts in young anaemic females. In this study it was found that, leucocyte counts, were significantly increased in anaemia. This increase was contributed mainly by neutrophils. A study conducted previously by Hrycek et $\mathrm{al}^{(7)}$, showed that there was an increase in neutrophil and basophil counts in anaemia, coinciding with this study.

Another study conducted by Paino et $\mathrm{al}^{(8)}$, showed that, lower oxidative increases life span of neutrophils. study done by Banerjee at $\mathrm{al}^{(9)}$,showed that phagocytic activity of neutrophils is reduced in anaemia. Thus increased counts, compensate for reduced phagocytic activity.

High leucocyte counts, increase the risk of vascular abnormality, and thrombotic phenomenon by several folds. Anaemia induces hypoxia, this hypoxia acts as a form of stress and increases the response or reactivity of blood vessels to catecolamines. Increased leucocyte count is most common indicator of inflammation. Due to inflammation of vessel wall, the leucocytes adher and release certain cytotoxic materials, certain hydrolytic enzymes bringing about damage of the vessel wall. ${ }^{(10)}$ These aggregated neutrophils, along with platelets damage the endothelium causing reperfusion injury and thus aggrevate already existing ischemic condition. Anaemia is said to be involved in the pathogenesis of chronic angina, heart failure, myocardial ischemia. ${ }^{(11)} \mathrm{A}$ recently emerged inflammatory index, which is easy to calculate, and also accurate, ie $\mathrm{N} / \mathrm{L}$ ratio. This ratio is highly useful IHD,MI etc ${ }^{(12,13)}$.In this study,N/L ratio was significantly increased in anaemic group as compared to control group

A study done by Akoy et $\mathrm{al}^{(14)}$ was done to evaluate effect of iron therapy on platelet function on women. It was found that, iron deficiency 
anaemia in women was responsible for arachidonic acid induced platelet dysfunction, and this could give rise to increased menstrual blood loss. This can be reversed through replenishment of iron stores. Kiem et $\mathrm{al}^{(15)}$ showed that, iron is present in platelet in platelets. In support to thus study, another study done by Karpatkin and colleagues $^{(16)}$ showed that iron has a functional role in controlling platelet production. It is also said that a two compartment model explains role of iron in maintaining platelet counts. Initially, Iron stores from the essential compartment are used up, resulting in low platelet counts ${ }^{(17)}$, which coincides with the present study

\section{Conclusion}

The present study concludes that, anaemia induces hypoxia, which in turn results in inflammation of vessel wall, resulting in ischemic damage and also aggrevating already existing ischemia. Anaemia increases the workload (hyperkinetic circulation) of myocardium. It induces thrombocytopenia, alters leucocyte counts thus increases N/L ratio. Thus anaemic individuals are at high risk of ischemic heart diseases, and bleeding tendencies.

\section{Acknowledgements}

I extend my immense gratitude to the entire Department of Physiology, RIMS, Raichur for their full time support, and guidance.

\section{References}

1. UNICEF/UNO/WHO/MI. Preventing iron deficiency in woman and children. Technical consensus on key issues. International Nutrition Foundation, Boston,MA;199 p.1-60.-

2. Butensky E, Harmatz P, Lubin B.Nutritional anaemias.nutrition in paediatrics.2008( $\left.4^{\text {th }}\right)$.-

3. Hercberg S,Galan P.Biochemical effects of iron depletion.Acta Pediatrics SCAND 1989;361(Suppl);63-70.-

4. Beard JL.Iron biology in immune function,muscle metabolism, and neuronal
functioning.J Nutr 2001;131(Suppl 2);56880

5. Ekiz C,AgaogluL,Karakas Z,Gurel $\mathrm{N}$, Yalchin I.The effect of iron deficiency anaemia on function of immune system. Hematol J 2005;5:579-83.

6. Hercberg S, Galan P.Biochemical effects of iron depletion.Acta Pediatric Scand 1989;361(Suppl):63-70.

7. Hrycek A,Kalina Z,Badowski R,Wartalska G.Spontaneous migration and adherence of leucocytes and NBT test of [peripheral blood neutrophils in patients with iron deficiency anaemia.Acta Haematol. Pol,1991;22-

8. Paino I M,Miranda JC,MarzocchiMachado CM.Cesarino EJ,de Castro FA,de Souza AM,Phagocytosis,oxidative burst,and produced reactive species are affected by iron deficiency anaemia and anaemia of chronic diseases in elderly.Biol Trace Elem.Res.,2009;129(1-3):116-125

9. Hrycek A,Kalina Z,Badowski R,Wartalska G.Spontaneous migration and adherence of leucocytes and NBT test of [peripheral blood neutrophils in patients with iron deficiency anaemia.Acta Haematol. Pol,1991;22-(2):261-266.

10. Ernst E, Bagge U.leucocyte and risk of ischemic disease.JAMA 1987; 257:23182324.

11. Chavan V, Patil N.Study of leucocytic hydrolytic enzyme in patients with acute stage of coronary heart disease.Ind. J Med Sci.2007;61:73-76.

12. Kuku I,Kaya E,Yologlu S,Gokdeniz R, Baydin A.Platelet counts in adults and iron deficiency anaemia.Platelets.2009 Sep ;20(6);401-5.

13. Akay OM,Akin E,Mutlu FS,Gulbas Z.Effect of iron therapy on platelet function among iron-deficient women with unexplained menorrhagia. Patholophysiol Haemost Thromb.2008;36(2);80-3. 
14. Kiem J,Borbrrg H,Iyengar GV,Kasperek K,Siegers M,Feinendegen LE,Gross

R.Elemental composition of platelets Part II.Water content of normal human platelets and measurements of their concentrations of $\mathrm{Cu}, \mathrm{F}, \mathrm{K}$, and $\mathrm{Zn}$ by neutron activation analysis.Clin Chem.1979;25:705-10.

15. Freedman ML,Karpatkin S.Requirement of iron for platelet protein synthesis. Biochem Biophys Res Commun. 1973;54:475-81

16. Gupta M,Joseph G.Severe thrombocytopenia associated with iron deficiency. Hospital Physician. 2001;37;49-54. 